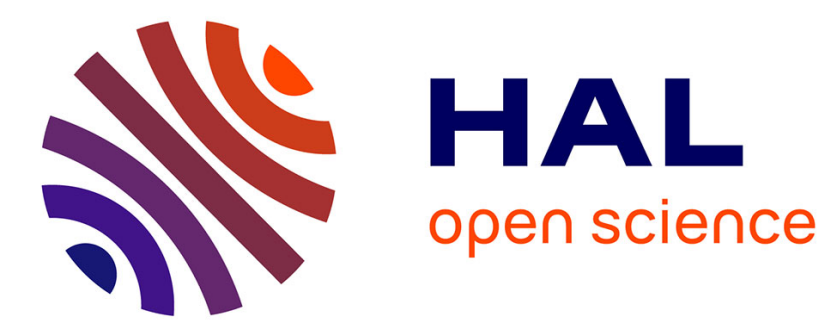

\title{
The asymmetric effect of environmental policy stringency on CO2 emissions in OECD countries
}

Claudiu Tiberiu Albulescu, Maria-Elena Boatca-Barabas, Andra Diaconescu

\section{To cite this version:}

Claudiu Tiberiu Albulescu, Maria-Elena Boatca-Barabas, Andra Diaconescu. The asymmetric effect of environmental policy stringency on CO2 emissions in OECD countries. 2021. hal-03303096

\section{HAL Id: hal-03303096 https://hal.science/hal-03303096}

Preprint submitted on 28 Jul 2021

HAL is a multi-disciplinary open access archive for the deposit and dissemination of scientific research documents, whether they are published or not. The documents may come from teaching and research institutions in France or abroad, or from public or private research centers.
L'archive ouverte pluridisciplinaire HAL, est destinée au dépôt et à la diffusion de documents scientifiques de niveau recherche, publiés ou non, émanant des établissements d'enseignement et de recherche français ou étrangers, des laboratoires publics ou privés. 
1 The asymmetric effect of environmental policy stringency on $\mathrm{CO}_{2}$ emissions

3 in OECD countries

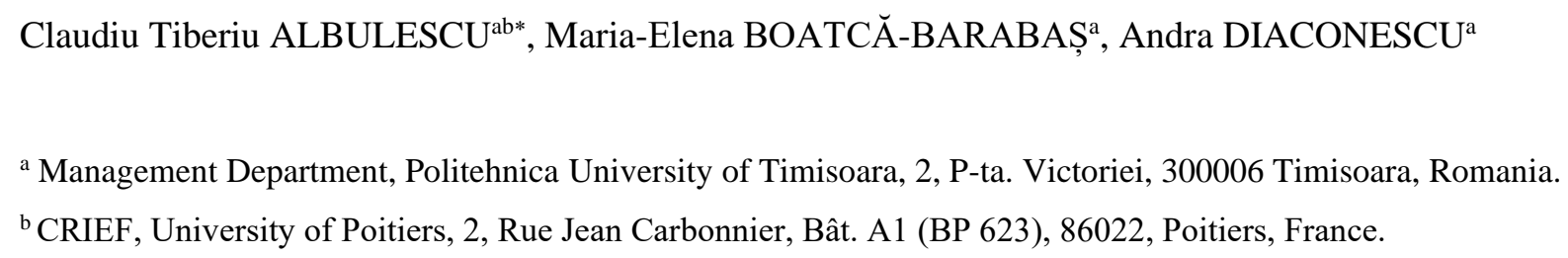

\section{Abstract}

This paper uses a quantile fixed-effect panel data approach to investigate how environmental policy stringency affects $\mathrm{CO}_{2}$ emissions in a set of $32 \mathrm{OECD}$ countries from 1990 to 2015. This approach allows us to identify the asymmetric impact of policy stringency on emissions, considering the emission level recorded in each analysed country. More precisely, we posit that the effectiveness of environmental regulations and policies is influenced by the air pollution level. Our results show that an increase in policy stringency has a negative impact on emissions. As a new contribution, we show that environmental stringency has a more powerful impact in the countries with lower level of carbon emissions. This result is also recorded for the subset of EU member countries of the OECD. Moreover, we show that policy stringency measures only become effective after the implementation of the Kyoto agreement. Finally, the policy stringency effect is stronger for EU countries at high risk of missing the 2020-20 target in terms of greenhouse gas emissions.

Keywords: $\mathrm{CO}_{2}$ emissions; environmental policies; environmental Kuznets curve; pollution haven hypothesis; panel quantiles regression.

JEL codes: Q43, Q56, F21

${ }^{*}$ Correspondence: Claudiu Tiberiu ALBULESCU, Politehnica University of Timisoara, P-ta. Victoriei, No. 2, 300006, Timisoara, Romania. Tel: 0040-743-089759. Fax: 0040-256-403021. E-mail: claudiu.albulescu@upt.ro, claudiual@yahoo.com.

Acknowledgements: This work was supported by a grant of the Romanian National Authority for Scientific Research and Innovation, CNCS-UEFISCDI, project number PN-III-P1-1.1-TE-2019-0436. 


\section{Introduction}

Environmental degradation in general, and the increase in greenhouse gas emissions in particular, requires urgent action and policy measures to fight against global warming. Although the European Union (EU) recorded an emission reduction by $24 \%$ between 1990 and $2019^{1}$, at the global level, emission levels are constantly rising. Most emissions are generated by the energy sector, which accounts, according to the International Energy Agency (IEA), for more than $80 \%$ of $\mathrm{CO}_{2}$ emissions (IEA 2019). In finding solutions to a low-carbon economy and increasing energy security, the guidelines of the Organization for Economic Cooperation and Development (OECD) for over 60 years has aimed at increasing and improving the quality of the environment, bringing to the fore stringent actions for climate change awareness. ${ }^{2}$ In fact, promoting green innovation and regulating emissions through carbon pricing are the two fundamental driving forces of climate change policies on carbon abatement (Hashmi and Alam 2019). Regarding the environmental policies and regulations of carbon emissions, environmental taxes and environmental policy stringency represent the main instruments used by authorities to fight against climate change (Wolde-Rufael and Mulat-Weldemeskel 2021).

Only a few empirical works, however, have assessed the efficiency of these instruments in moving down the emission level (e.g. Albulescu et al. 2020; Hashmi and Alam 2019; Ma et al. 2018; Niedertscheider et al. 2018; Wenbo and Yan 2018; Zhao et al. 2015). A portion of these works (Wang et al. 2020a; Wolde-Rufael and Mulat-Weldemeskel 2021) investigate the effectiveness of environmental policy stringency in reducing $\mathrm{CO}_{2}$ emissions. Stringency is associated with a specific pollution price imposed by environmental policies. The OECD computes a specific environmental policy stringency index (EPSI), combining market-based (taxation, trading schemes, deposit and refund schemes, etc.) with non-market-based policies (standards and limitations, research and development expenditures, etc.). ${ }^{3}$ While Wang et al. (2020a) investigated the EPSI's impact on air pollution, with a focus on different dimensions of air pollution in 23 OECD countries from 1990 to 2015, more recently Wolde-Rufael and Mulat-Weldemeskel (2021) have tested the U-shaped relationship between $\mathrm{CO}_{2}$ emissions and EPSI for a set of seven emerging economies.

\footnotetext{
${ }^{1}$ https://ec.europa.eu/clima/policies/strategies/progress en

2 According to Sadik-Zada and Ferrari (2020), over 90\% of the population in OECD countries are aware of climate change, and over $60 \%$ of them believe that climate change poses a serious threat to sustainable livelihoods and international security.

${ }^{3} \mathrm{https} / / / \mathrm{www}$.oecd.org/environment/how-stringent-are-environmental-policies.htm
} 
We add to this narrow strand of the literature, and we analyse the non-linear and asymmetric effect of environmental policy stringency on carbon emissions in a set of 32 countries, using OECD data and the fixed-effect quantile panel data approach by Canay (2011). Our empirical investigation covers the period from 1990 to 2015.

Consequently, we contribute to the existing literature as follows. First, we argue that the environmental policy stringency effect on $\mathrm{CO}_{2}$ emissions is influenced by the emission level recorded in each analysed country. This way, we can shed light on the mixed findings reported so far in the literature, showing either a significant (e.g. Zhao et al. 2015) or an insignificant (e.g. Niedertscheider et al. 2018) impact of environmental regulation on carbon emissions. Indeed, the impact of policy stringency on $\mathrm{CO}_{2}$ emissions is asymmetric, being influenced by the pollution level. This is because policy measures should target specific pollution sources and their magnitude should be correlated with the pollution intensity. However, we cannot say a priori whether the increase in policy stringency will lead to a stronger reduction in environmental degradation in the countries with lower or higher pollution levels. On the one hand, if the emission levels record higher dynamics (the case of emerging economies), the authorities will be forced to adopt more restrictive policy measures to prevent environmental degradation. On the other hand, the authorities from the countries which are exposed to additional environmental constraints as regional targets or policies (the EU case), even in the presence of negative dynamics of carbon emissions, might be forced to take action and enhance the policy stringency. If this is the case, the environmental regulations have a more powerful impact in the countries with lower levels of carbon emissions. Canay's (2011) approach will allow us to verify and test these hypotheses. As far as we know, this is the first paper which resorts to a fixed-effect quantile panel data approach to investigate the relationship between environmental policy stringency and $\mathrm{CO}_{2}$ emissions.

Second, we perform a series of analyses to see whether the asymmetric effect of EPSI on $\mathrm{CO}_{2}$ emissions also manifest inside the EU group of OECD member countries or whether this effect is stronger after the adoption of the Kyoto protocol. For example, Albulescu et al. (2020) has shown that the entry into force of the Kyoto protocol has had no significant effect on carbon emissions in EU countries, whereas the "Climate and Energy Package 2020" adopted in 2009 has had only a marginal effect on $\mathrm{CO}_{2}$ emissions.

Third, we perform a deeper analysis of the EU sample of OECD member states, and we split the group into two parts, considering the countries at risk and not at risk of achieving the 20-20-20 target. We posit that countries that are in a position to miss the target over the analysed time horizon will take more vigorous actions to prevent environmental degradation. 
Finally, in line with previous papers on this topic, we check the environmental Kuznets curve (EKC) and the pollution haven hypotheses( $\mathrm{PHH})$. To this end, similar to Albulescu et al. (2020) and Apergis and Ozturk (2015), we address the endogeneity effect between emissions and foreign direct investment (FDI). Moreover, we posit that the endogeneity effect might also manifest between carbon emissions and environmental policy stringency. Indeed, if carbon emissions are high, this element could force the authorities to impose more stringent policy measures.

To preview our findings, we show that policy stringency has a negative impact on $\mathrm{CO}_{2}$ emissions. That is, more restrictive environmental policies and measures contribute to a reduction in emissions. Interestingly, we document that environmental regulations and restrictions have a stronger impact on carbon emissions in countries with a lower level of emissions (i.e. EU countries). Our results thus confirm the findings by Hashmi and Alam (2019) and Wang et al. (2020a), showing the negative impact of EPSI on carbon emissions in OECD countries. However, as a new contribution, we show that the impact is asymmetric and more powerful for lower quantiles, that is, for countries with a lower level of emissions. This result proves the efficiency of EU environmental regulations compared to the effect of similar regulations in other OECD member states.

The rest of the paper presents a review of the literature (Section 2), the data and methodology (Section 3), the main empirical findings (Section 4) and the robustness checks (Section 5). The last section concludes with the asymmetric impact of environmental policy stringency on carbon emissions.

\section{Literature review}

Acknowledgment of environmental degradation brought stringent actions from different countries around the world that introduced policy stringency instruments (e.g. environmental taxes, trading schemes, emission standards, etc.) in response to environmental challenges (Machiba 2010). One of the strictness measures was developed by Botta and Koźluk (2014) through the environmental policy stringency index, distinguishing between market-based instruments and non-market ones. EPSI focuses on climate and air policies in key upstream sectors and combines information on selected environmental policies to create a composite measure of relative policy across countries over a period of time, which represents its main advantage (for additional explanations, please refer to Botta and Koźluk 2014). The use of EPSI is based on different assumptions. The first assumption is that the omission of certain types of 
instruments creates heterogeneity between countries, which makes comparison of their stringency across time and eventually across countries problematic. Thus, in the recent research, there are some interpretations of EPSI in terms of multidimensionality, sampling, identification (and enforcement) and lack of data (Brunel and Levinson 2013; Koźluk and Zipperer 2015). The second assumption can prove that the stringency of environmental policies encourages green innovation and works to set international standards to improve economic performance. In this line, the research conducted by Ahmed (2020), Martínez-Zarzoso et al. (2019), Wang et al. (2020a, 2020b), Ouyang et al. (2019) resorted to policy instruments for innovation, productivity, technological innovation and green growth.

The applicability of EPSI has therefore caught the attention of researchers and was employed in investigating the connection between climate change and economic growth (e.g. De Angelis et al. 2019) or in assessing the impact of environmental regulations in reducing greenhouse gases (e.g. Ahmed and Ahmed 2018). However, recent literature strongly emphasises that the unavailability of a reliable measure of environmental policy strictness generates an asymmetric response to environmental issues among countries (Galeotti et al. 2020). Therefore, the OECD measure of policy stringency represents a reliable indicator to perform cross-country analyses. Figure 1 describes the construction logic of the EPSI index.

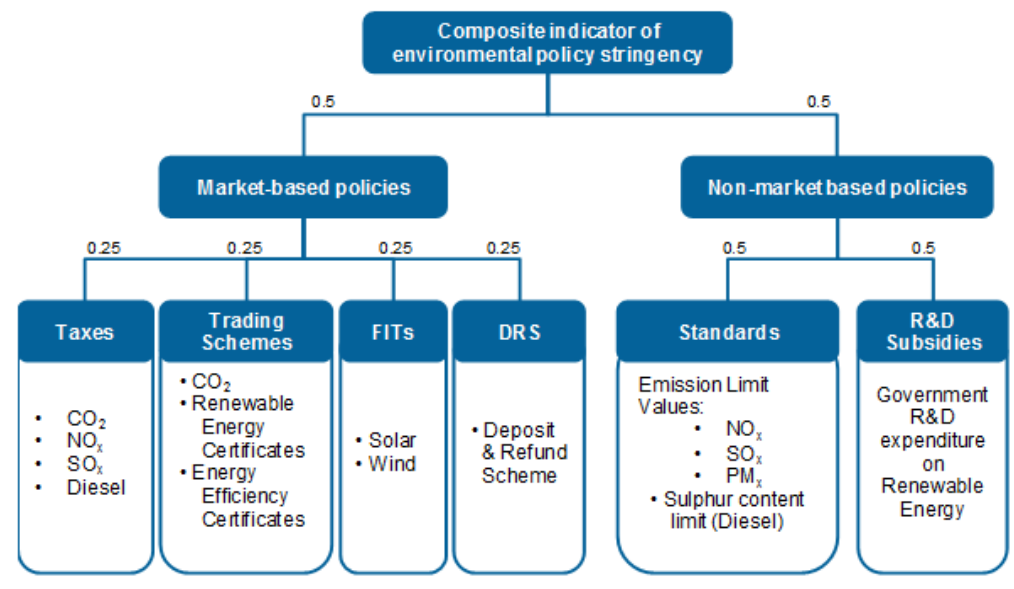

Fig. 1 The OECD Environmental Policy Stringency Index Source: https://www.oecd.org/economy/greeneco/how-stringent-are-environmental-policies.htm

\subsection{The effectiveness of environmental regulations and policies}

The role of global political debates on environmental degradation is to search for solutions by identifying the best policy mechanisms for a sustainable environment. Following these political debates, some research has arisen that is closely linked to environmental policies (Boyd 
et al. 1995; Ma et al. 2018; Simões et al. 2008; Yin et al. 2015; Zhao et al. 2015), economic growth modelling (Pao et al. 2011), the impact of pollution on the environment and energy consumption (Benvenutti et al. 2019; Li et al. 2017; Mao et al. 2012).

The effectiveness of environmental regulations might be explained by two driving forces, namely the political willingness to achieve the environmental targets and the trade-off between economic and environmental short-run objectives.

First, the implementation of environmental policies is closely linked to the political parties in power. For example, Asafu-Adjaye and Mahadevan (2013) underlined the fact that a focus of the Australian government on distortionary state and federal taxes, such as income tax, savings tax, property tax and indirect taxes, may negate the efficiency gains of the emissions trading scheme (ETS). In Austria, Niedertscheider et al. (2018) indicated some concerns regarding the future of climate policy integration (CPI) due to the perpetuation of the conflict "economic growth versus climate protection" by political parties. The authors showed that political parties are closely connected to the business environment, which negatively affects the implementation of $\mathrm{CO}_{2}$ emission decisions and policies. Further, policy adjustments also influence the impact of economic and social factors on $\mathrm{CO}_{2}$ emissions (Huo et al. 2015).

Second, the economic interest of some countries might affect the effectiveness of their environmental regulations. This is the case for emerging market economies, which record high economic growth rates. In this context, one book in the literature under review addressed the case of China, analysing the effectiveness of environmental regulations in specific industries or its overall effect on climate change. In this line, Ma et al. (2018) analysed whether government regulations influence the efficiency of the mining sector in China and identify heterogeneity in the effect of regulations according to property type. The authors stated that the absence of an effective incentive, a monitoring mechanism and a deviation from the profit maximisation objective hinders eco-efficient performance. They proposed market-oriented regulatory instruments, such as tax breaks and subsidies, for private enterprises, and for state-owned enterprises, command-and-control instruments combined with appropriate target-based regulations. Similarly, Xu et al. (2018) have pointed out that coal tax policy reform is conducive to promoting reductions in emissions and environmental benefits, but the impact is different when different tax rates are used. The 5\% tax rate on coal resources can effectively inhibit excessive resource consumption, improve resource efficiency and reduce environmental damage, which can be a reasonable choice to reduce $\mathrm{CO}_{2}$ emissions in China. Wenbo and Yan (2018) analysed in their turn the relationship between $\mathrm{CO}_{2}$ emissions and energy consumption in 30 regions of China between 2004-2015, using Tapio decoupling models, GMM differential 
methods and peak forecasting models. They controlled for the role of environmental regulations and discovered an inverted U-shaped relationship between environmental regulations and $\mathrm{CO}_{2}$ emissions. In the same spirit, Zhao et al. (2015) conducted an empirical study on 137 power plants in China and performed a micro-level analysis of the role of environmental regulations. They concluded that market-based regulations and government subsidies help to reduce the $\mathrm{CO}_{2}$ emissions of China's power plants. In contrast, Cheng et al. (2017) showed that command-andcontrol policy tools are conducive to emissions reduction, but their effects on technical progress are not significant; market-based policy tools are conducive to technical progress, but their effects on emissions reduction are relatively weak.

A different approach has been taken by Mao et al. (2012), who compared the effectiveness of various policy instruments, such as $\mathrm{CO}_{2}$ tax, fuel tax and energy tax, on influencing carbon emissions. Among these instruments, energy and fuel taxes are the two most promising instruments for $\mathrm{CO}_{2}$ emission intensity reduction, and subsidies are the least promising options. The authors also show that $\mathrm{CO}_{2}$ tax could be an effective policy tool. With a focus on three types of environmental policies in China (energy structure policies, energy efficiency improving policies and production scale policies), Li et al. (2018) demonstrated that $\mathrm{CO}_{2}$ reduction benefits a lot from cleaner electricity generation. The connection between environmental policies and $\mathrm{CO}_{2}$ emissions was recorded for all categories of policies.

Other similar studies have focused on Chile (Mardones and Flores 2018), Malaysia (Yahoo and Othman 2017) or BRICS countries as a group (Adedoyin et al. 2020), and have underlined the importance of environmental taxes, abatement policies and coal rents on the reduction of $\mathrm{CO}_{2}$ emissions. Table A1 (Appendix), presents a comparison of early studies focusing on the effectiveness of environmental regulations and policies.

\subsection{Environmental policy stringency and $\mathrm{CO}_{2}$ emissions in $\mathrm{OECD}$ countries}

As previously mentioned, a reliable approach to identify the effectiveness of environmental regulations and policies on environmental pollution is to consider an aggregate policy stringency index. OECD countries have worked together to establish policy measures to reduce the impact of economic activities that have negative effects on society and environment (Johnstone et al. 2012). One measure was the construction of EPSI in 2014. Since then, several recent empirical papers have addressed the non-linear effect of environmental regulations on carbon emissions. 
Likewise, the paper by Álvarez et al. (2017) explores the impact of improvements in energy innovation - an EPSI component - on GHG emissions in 28 OECD countries for the period of 1990-2014. They showed that the effect of energy innovation on environmental correction requires a significant time lag. Similar, Hashmi and Alam (2019) examined the effects of environmental regulation and innovation on the carbon emission reduction of OECD countries during the period 1999-2014 and aimed to optimise market-based instruments, such as patents and carbon pricing, for the implementation of efficient and cost-effective climate change policies. At the same time, Ahmed (2020) has argued that stringent environmental policies coupled with environmentally friendly innovation are the impetus for sustainable development. A different approach was taken by Ahmed and Ahmed (2018) who considered environmental policy stringency and economic activity as controlling variables in forecasting $\mathrm{CO}_{2}$ emissions in China. Sadik-Zada and Ferrari (2020) employed in their turn the EPSI to test the EKH and PHH in a set of 26 OECD countries over the period 1995 to 2011.

More recently, Ouyang et al. (2019) found an inverted U-shaped relationship between the environmental policy stringency index and PM2.5 emissions for 30 OECD countries. A similar result was reported by Wolde-Rufael and Mulat-Weldemeskel (2021), who documented the existence of an inverted U-shaped relationship between $\mathrm{CO}_{2}$ emissions and EPSI, suggesting that it takes time for environmental policy stringency measures to be effective. Finally, Wang et al. (2020b) analysed the strictness of environmental regulatory policies and measured the

\section{Data and methodology}

\subsection{Data}

We use annual data from 1990 to 2015 (OECD statistics) to analyse the emissionsenvironmental regulation nexus, with a focus on 32 countries (Table A2-Appendix). EPSI 
represents our variable of interest, and it is used as a proxy for environmental regulations. These data are available until 2015 only. However, the time span we analysed is long enough to identify the effect of worldwide major changes in terms of environmental policies and regulations at a global level (e.g. the entry into force of the Kyoto protocol) or the effect of environmental and climate change policies at the EU level (e.g. 20-20-20 targets) on carbon emissions.

In line with previous papers assessing the impact of environmental regulations on air pollution levels (e.g. Albulescu et al. 2019, 2020; Ma et al. 2018; Niedertscheider et al. 2018; Sapkota and Bastola 2017; Wenbo and Yan 2018; Zhao et al. 2015), we focus on the $\mathrm{CO}_{2}$ emissions (metric tons per capita). These data are extracted from the World Development Indicators database (World Bank). The explanatory variables come from the same database and are represented by the level of GDP per capita, expressed in natural log (which allows us to test the EKC hypothesis), the net inflows of FDI as a percentage of GDP (necessary to test the $\mathrm{PHH}$ ), the energy use (kg of oil equivalent per capita in natural $\log$ ) and the renewable energy consumption as a percentage of total final energy consumption.

A series of other control variables have been advanced in the literature to check the determinants of $\mathrm{CO}_{2}$ emissions (i.e. human capital, gross fixed capital formation, population density, unemployment rate, etc.). However, as Albulescu et al. (2020) have shown, the impact of these variables is either reduced or insignificant. Therefore, we have focused on the main drivers of carbon emissions, which are the energy consumption and economic growth levels while placing special emphasis on the role of environmental regulations and policies. We also address the potential impact of using renewable energy on $\mathrm{CO}_{2}$ emissions. Most previous studies have shown that this impact is marginal (e.g. Aliprandi et al. 2016; Chen et al. 2019; Dong et al. 2018), although the use of renewables represents a promising solution to control and mitigate air pollution levels. The descriptive statistics of our variables are presented in Table 1.

Table 1. Descriptive statistics

\begin{tabular}{llllll}
\hline Variables & Observations & Mean & Std. Dev. & Min & Max \\
\hline $\mathrm{CO}_{2}$ & 823 & 8.283 & 4.116 & 0.709 & 20.17 \\
$\mathrm{EPSI}$ & 776 & 1.584 & 0.963 & 0.208 & 4.133 \\
$\mathrm{GDP}$ & 824 & 9.944 & 1.063 & 6.355 & 11.42 \\
$\mathrm{GDP}$ & 824 & 100.0 & 19.73 & 40.38 & 130.5 \\
$\mathrm{FDI}$ & 823 & 3.776 & 7.396 & -15.83 & 86.58 \\
$\mathrm{EU}$ & 826 & 8.040 & 0.649 & 5.858 & 9.042 \\
$\mathrm{RTEC}$ & 832 & 16.97 & 15.84 & 0.441 & 61.37 \\
\hline
\end{tabular}

Notes: $\mathrm{CO}_{2}$ - carbon emission, EPSI-Environmental Policy Stringency Index, GDP—GDP per capita, GDP — ${ }^{2}$ squared GDP per capita, FDI — net FDI inflows, EU—energy use, RTEC — renewable to total electricity consumption. 


\subsection{Methodology}

We ran a panel regression model in quantiles to account for non-linearities and asymmetry in the tested relationship, and we used Canay's (2011) approach with fixed effects to account for unobserved covariates. The general equation we tested is (we used the first lag of explanatory variables to avoid any endogeneity bias):

$\mathrm{co}_{2 i t}=\alpha_{0}+\alpha_{1} e p s i_{i t-1}+\alpha_{2} Z_{i t-1}+\mu_{i}+\gamma_{t}+\varepsilon_{i t}$,

where $\mathrm{CO}_{2 i t}$ are the carbon emissions (metric tons per capita) of the country $i$ in the year $t ; \alpha_{0}$ represents the intercept; $e p s i_{i t-1}$ is the environmental policy stringency index; $Z_{i t-1}$ is the vector of control variables represented by GDP per capita, FDI, energy use ( $\mathrm{kg}$ of oil equivalent per capita) and the renewable energy consumption (\% of total final energy consumption); $\mu_{i}$ are the time-invariant firm specific effects, $\gamma_{t}$ are the time-specific effects and $\varepsilon_{i t}$ are the error terms.

A series of panel quantile fixed-effects models are proposed in the literature (e.g. Canay 2011; Galvao 2011; Koenker 2004; Lamarche 2010; Rosen 2012). These models might be described as follows:

$Y_{i t}=X_{i t}^{\prime} \theta\left(U_{i t}\right)+\alpha_{i}$,

where $t=1, \ldots, T ; i=1, \ldots, n ; Y_{i t}$ and $X_{i t}$ represent observable variables; $U_{i t}$ is an unobservable component; $X_{i t}^{\prime}$ includes a constant term and $\theta(\tau)$ is the parameter of interest.

If the function $\tau \rightarrow X^{\prime} \theta(\tau)$ is increasing in $\tau \in(0,1)$, for an observable $\alpha_{i}$, we have $P\left[Y_{i t} \leq X_{i t}^{\prime} \theta\left(U_{i t}\right)+\alpha_{i} \mid X_{i}, \alpha_{i}\right]=\tau$, where $U_{i t} \sim U[0,1]$, conditional on $X_{i}=\left(X_{i 1}^{\prime}, \ldots, X_{i T}^{\prime}\right)^{\prime}$ and $\alpha_{i}$.

For all these models, the challenge is to correctly identify $\theta(\tau)$. If $Q_{Y}(\tau \mid X)$ is the $\tau$ quantile of a random variable $Y$ conditional on $X$ and $e_{i t}(\tau) \equiv X_{i t}^{\prime}\left[\theta\left(U_{i t}\right)-\theta(\tau)\right]$, equation (2) becomes

$Y_{i t}=X_{i t}^{\prime} \theta\left(U_{i t}\right)+\alpha_{i}+e_{i t}(\tau)$.

By assuming that $\alpha_{i}$ is a location shift, Canay (2011) proved that $\theta(\tau)$ is identified for $T \geq 2$ under independence restrictions and existence of moments. In fact, Canay (2011) assumed that only $\theta(\tau)$ and $e_{i t}(\tau)$ depend on $\tau$ and transforms equation (1) as follows:

$Y_{i t}=X_{i t}^{\prime} \theta \mu+\alpha_{i}+u_{i t}, \quad E\left(u_{i t} \mid X_{i}, \alpha_{i}\right)=0$.

This transformation represents the novelty of Canay's (2011) approach, which allows the author to compute the two-step estimator $\hat{\theta} \mu$. In the first step, a consistent estimator of $\alpha_{i}(\sqrt{T})$ 
and $\theta \mu(\sqrt{n T})$ is obtained, with $\hat{\alpha}_{i} \equiv E_{T}\left[Y_{i t}-X_{i t}^{\prime} \hat{\theta} \mu\right]$. In the second step, the author defines $\hat{Y}_{i} \equiv Y_{i t}-\hat{\alpha}_{i}$, whereas $\hat{\theta} \mu$ becomes

where $\mathbb{E}_{n T}(\cdot) \equiv(n T)^{-1} \sum_{t=1}^{T} \sum_{i=1}^{n}(\cdot)$

\section{Results}

The main empirical results are presented in Table 2. Firstly, we noticed that the impact of EPSI on carbon emission was negative and very significant, except for the extreme upper quantiles. This means that an increase of environmental policy stringency results in a decrease in $\mathrm{CO}_{2}$ emissions. The findings are therefore consistent with those reported by Albulescu et al. (2020) for the EU countries and by Zhao et al. (2015) for China, but they contradict those reported by Niedertscheider et al. (2018) for Australia. As a new contribution, we have shown that environmental stringency has a more powerful impact in the countries with lower levels of carbon emissions (that is, for the lower quantiles) compared to the high polluters.

Table 2. Panel conditional quantile regression — entire sample

\begin{tabular}{|c|c|c|c|c|c|c|c|c|c|c|}
\hline \multirow[t]{2}{*}{ Quantiles } & \multicolumn{3}{|c|}{ Lower } & \multicolumn{4}{|c|}{ Middle } & \multicolumn{3}{|c|}{ Upper } \\
\hline & 0.05 & 0.15 & 0.25 & 0.35 & 0.45 & 0.55 & 0.65 & 0.75 & 0.85 & 0.95 \\
\hline \multirow[t]{2}{*}{ EPSI } & $-0.248 * * *$ & $-0.297 * * *$ & $-0.219 * * *$ & $-0.214 * * *$ & $-0.212 * * *$ & $-0.202 * * *$ & $-0.196 * * *$ & $-0.107 * * *$ & $-0.098 * *$ & $0.178 * *$ \\
\hline & $\begin{array}{l}(0.079) \\
\end{array}$ & $(0.065)$ & $(0.044)$ & $(0.029)$ & \begin{tabular}{|l|}
$(0.028)$ \\
\end{tabular} & $(0.033)$ & $(0.038)$ & $(0.041)$ & $(0.045)$ & $(0.070)$ \\
\hline \multirow[t]{2}{*}{ GDP } & $4.866 * * *$ & $3.357 * * *$ & $2.331 * * *$ & $2.378 * * *$ & $2.266 * * *$ & $2.565 * * *$ & $2.086 * * *$ & $1.754 * * *$ & $1.199 * *$ & 1.038 \\
\hline & $(0.963)$ & $(0.785)$ & $(0.539)$ & $(0.354)$ & $(0.337)$ & $(0.397)$ & $(0.461)$ & $(0.501)$ & $(0.546)$ & $(0.850)$ \\
\hline \multirow[t]{2}{*}{ GDP $^{2}$} & $-0.292 * * *$ & $-0.206 * * *$ & $-0.151 * * *$ & $-0.155^{* * *}$ & $-0.149 * * *$ & $-0.166 * * *$ & $-0.142 * * *$ & $-0.128 * * *$ & $-0.100 * * *$ & $-0.094 * *$ \\
\hline & $(0.051)$ & $(0.042)$ & $(0.0$ & $(0.019)$ & $(0.018)$ & $(0.021)$ & $(0.025)$ & $(0.027)$ & $(0.029)$ & $(0.045)$ \\
\hline \multirow[t]{2}{*}{ FDI } & 0.011 & 0.011 & 0.005 & 0.004 & 0.004 & 0.001 & 0.000 & -0.004 & -0.003 & 0.006 \\
\hline & $(0.009)$ & $(0.008)$ & $(0.005)$ & $(0.003)$ & $(0.003)$ & $(0.004)$ & $(0.004)$ & $(0.005)$ & $(0.005)$ & $(0.008)$ \\
\hline \multirow[t]{2}{*}{ EU } & $2.896 * * *$ & $3.010 * * *$ & $3.064 * * *$ & $3.236 * * *$ & $3.277 * * *$ & $3.295 * * *$ & $3.382 * * *$ & $3.555 * * *$ & $3.616 * * *$ & $3.866^{* * * *}$ \\
\hline & $(0.180)$ & $(0.146)$ & $(0.101)$ & $(0.066)$ & $(0.063)$ & $(0.074)$ & $(0.086)$ & $(0.094)$ & $(0.102)$ & $(0.159)$ \\
\hline \multirow[t]{2}{*}{ RTEC } & $-0.042 * * *$ & $-0.048 * * *$ & $-0.048 * * *$ & $-0.046 * * *$ & $-0.044 * * *$ & $-0.040 * * *$ & $-0.040 * * *$ & $-0.038 * * *$ & $-0.037 * * *$ & $-0.029 * * *$ \\
\hline & $(0.005)$ & $(0.004)$ & $(0.003)$ & $(0.0$ & $(0.002)$ & $(0.0$ & $(0.002)$ & $(0.003)$ & $(0.003)$ & $(0.004)$ \\
\hline \multirow[t]{2}{*}{$\alpha_{0}$} & $-34.12 * * *$ & $-27.92 * * *$ & $-23.55 * * *$ & $-24.82 * * *$ & $-24.56^{* * *}$ & $-26.00 * * *$ & $-24.15 * * *$ & $-23.57 * * *$ & $-21.26^{* * *}$ & $-22.35 * * *$ \\
\hline & $(4.432)$ & $(3.615)$ & $(2.482)$ & $(1.632)$ & $(1.552)$ & $(1.826)$ & $(2.121)$ & $(2.307)$ & $(2.514)$ & (3.914) \\
\hline
\end{tabular}

In line with most previous papers on the topic, we noted the importance of energy use for $\mathrm{CO}_{2}$ emissions, and we validated the EKC hypothesis at all quantiles, except for the extreme upper quantiles. The effect of inward FDI was insignificant, a result that explains the mixed findings previously reported by the literature. For example, Sapkota and Bastola (2017) and Albulescu et al. (2019) found evidence for the PHH in the case of Latin American countries, 
whereas Albulescu et al. (2020) documented opposite findings for EU countries and validated the pollution halo hypothesis.

The impact of the share of renewables in total electricity consumption had a negative impact on emissions, although the effect was reduced. This impact is stronger for lower quantiles, that is, for lower emissions levels. Our results validate most of the previous findings underlining the positive role of renewables in the reduction of carbon emissions (e.g. Albulescu et al. 2020; Aliprandi et al. 2016; Chen et al. 2019; Dong et al. 2018; Inglesi-Lotz and Dogan 2018; Sinha and Shahbaz 2018; Zoundi 2017).

Our sample contains data on a large set of OECD countries but also information about carbon emissions in several emerging countries. In addition, several international treaties were concluded to fight against climate change during the analysed timespan. Therefore, to check the robustness of our findings, we first assessed the impact of the entry into force of Kyoto protocol, namely in 2005. To this end, we worked on two subsamples covering the periods 1990 to 2004 and 2004 to 2015. Second, we focused on the EU countries sample. It is well known that the EU acts as an international leader in fighting against greenhouse gas (GHG) emissions. The EU established precise targets in terms of GHG emissions, renewable energy, and energy efficiency to be achieved in 2020 (the so-called 20-20-20 targets). However, the progressive monitoring of reaching those targets showed that several countries were in difficulty and risked missing the targets. For example, during the 2016 monitoring of the European Commission ${ }^{4}$, in the case of four EU countries (Austria, Belgium, Denmark and Ireland), the projected progress underlined some issues in terms of GHG emissions targets. Consequently, we also compared the impact of environmental policy stringency for EU countries not at risk of achieving the 2020-20 target in terms of GHG emissions with those at risk of missing the targets.

\section{Robustness check}

\subsection{The impact of the Kyoto protocol's entry into force}

The Kyoto protocol was adopted in 2003, and its effective entry into force happened in 2005. Consequently, we first looked at the pre-Kyoto period and surprisingly noticed that the sign of EPSI was positive and significant, meaning that previous environmental regulations were completely inefficient in fighting against climate change. The results reported in Table 3

\footnotetext{
$4 \mathrm{https} / / / \mathrm{www}$. eea.europa.eu/themes/climate/trends-and-projections-in-europe/trends-and-projections-in-europe2016/1-overall-progress-towards-the
} 

emissions.

Table 3. Panel conditional quantile regression — entire sample before Kyoto protocol

\begin{tabular}{|c|c|c|c|c|c|c|c|c|c|c|}
\hline \multirow[t]{2}{*}{ Quantiles } & \multicolumn{3}{|c|}{ Lower } & \multicolumn{4}{|c|}{ Middle } & \multicolumn{3}{|c|}{ Upper } \\
\hline & 0.05 & 0.15 & 0.25 & 0.35 & 0.45 & 0.55 & 0.65 & 0.75 & 0.85 & 0.95 \\
\hline \multirow[t]{2}{*}{ EPSI } & 0.085 & 0.193 & $0.124 *$ & $0.163 * *$ & $0.122 * *$ & 0.092 & $0.230 * * *$ & $0.355 * * *$ & $0.403 * * *$ & 0.495 \\
\hline & $(0.182)$ & $(0.088)$ & $(0.072)$ & $(0.066)$ & $(0.061)$ & $(0.058)$ & $(0.062)$ & $(0.077)$ & $(0.108)$ & $(0.182)$ \\
\hline \multirow[t]{2}{*}{ GDP } & -0.505 & -0.616 & -0.704 & -0.483 & -0.579 & -0.315 & -0.045 & -0.099 & -0.191 & 0.422 \\
\hline & $(1.235)$ & $(0.596)$ & $(0.488)$ & $(0.446)$ & $(0.417)$ & $(0.393)$ & $(0.420)$ & $(0.522)$ & $(0.735)$ & $(1.234)$ \\
\hline \multirow[t]{2}{*}{$\mathrm{GDP}^{2}$} & 0.023 & 0.034 & 0.037 & 0.024 & 0.032 & 0.018 & 0.001 & 0.003 & 0.007 & -0.037 \\
\hline & $(0.067)$ & $(0.032)$ & $(0.027)$ & $(0.024)$ & $(0.0$ & $(0.021)$ & $(0.023)$ & $(0.028)$ & $(0.040)$ & $(0.067)$ \\
\hline \multirow[t]{2}{*}{ FDI } & 0.012 & 0.011 & 0.007 & -0.0 & -0. & 1 & 0.0 & -0.001 & 0.010 & $0.033^{*}$ \\
\hline & $(0.0$ & $(0.009)$ & $(0.007)$ & $(0.006)$ & $(0)$. & 96) & $(0$. & $(0.008)$ & $(0.011)$ & $(0.018)$ \\
\hline \multirow[t]{2}{*}{$\mathrm{EU}$} & $0.666 * * *$ & $0.575 * * *$ & $0.762 * * *$ & $0.842 * * *$ & $0.788 * * *$ & $0.782 * * *$ & $0.859 * * *$ & $0.907 * * *$ & $0.991 * * *$ & $1.318 * * *$ \\
\hline & $(0.242)$ & $(0.117)$ & $(0.096)$ & $(0.088)$ & $(0.082)$ & $(0.077)$ & $(0.082)$ & $(0.102)$ & $(0.144)$ & $(0.242)$ \\
\hline \multirow[t]{2}{*}{ RTEC } & $0.019 * * *$ & $0.011 * * *$ & $0.013 * * *$ & $0.015^{* * *}$ & $0.012 * * *$ & $0.011 * * *$ & $0.014 * *$ & $0.015 * *$ & $0.014 * * *$ & $0.016^{* *}$ \\
\hline & $(0.007)$ & $(0.003)$ & $(0.0$ & $(0.002)$ & $(0.0$ & $(0.0$ & $(0.0$ & $(0.003)$ & $(0.004)$ & $(0.007)$ \\
\hline \multirow[t]{2}{*}{$\alpha_{0}$} & 4.331 & $5.560 * *$ & $4.848 * *$ & $3.463 *$ & $4.268 * *$ & $3.245^{*}$ & 1.564 & 1.491 & 1.429 & -2.790 \\
\hline & $(5.667)$ & $(2.734)$ & $(2.240)$ & $(2.048)$ & $(1.913)$ & $(1.801)$ & $(1.928)$ & $(2.394)$ & (3.374) & $(5.660)$ \\
\hline
\end{tabular}

Table 4, however, presents a different situation. It clearly shows that the entry into force of the Kyoto protocol enhanced the environmental policy stringency, with a negative impact on carbon emissions. Again, the impact was higher for lower polluter countries.

Table 4. Panel conditional quantile regression — entire sample after Kyoto protocol

\begin{tabular}{|c|c|c|c|c|c|c|c|c|c|c|}
\hline \multirow[t]{2}{*}{ Quantiles } & \multicolumn{3}{|c|}{ Lower } & \multicolumn{4}{|c|}{ Middle } & \multicolumn{3}{|c|}{ Upper } \\
\hline & 0.05 & 0.15 & 0.25 & 0.35 & 0.45 & 0.55 & 0.65 & 0.75 & 0.85 & 0.95 \\
\hline \multirow[t]{2}{*}{ EPSI } & $-0.414 * * *$ & $-0.357 * * *$ & $-0.472 * * *$ & $-0.426 * * *$ & $-0.425 * * *$ & $-0.457 * * *$ & $-0.455 * * *$ & $-0.364 * * *$ & $-0.335 * * *$ & $-0.295^{*}$ \\
\hline & $(0.113)$ & $(0.103)$ & $(0.087)$ & $(0.065)$ & $(0.060)$ & & $\begin{array}{l}(0.077) \\
\end{array}$ & $(0.078)$ & $\begin{array}{l}(0.088) \\
\end{array}$ & $(0.177)$ \\
\hline \multirow[t]{2}{*}{ GDP } & 13. & 13.0 & 12 . & 11.9 & & & $* * *$ & 10.5 & $9.799 * *$ & \\
\hline & (1. & (1.296) & & (0. & (0. & (0. & (0. & $(0 .)^{-}$ & $(1.100)$ & (2. \\
\hline \multirow[t]{2}{*}{ GDP } & -0.67 & $-0.674 * * *$ & -0.61 & -0.617 & $-0.597 * * *$ & $-0.566 * * *$ & $-0.537 * * *$ & $-0.544 * * *$ & $-0.505 * * *$ & -0.4 \\
\hline & $(0.0$ & $(0.068)$ & $(0.0$ & $(0)$. & $(0$. & $(0$. & $(0.051)$ & $(0.051$ & $(0.057)$ & $(0$. \\
\hline \multirow[t]{2}{*}{ FDI } & 0. & 6 & & 0. & 0. & -0. & -0.0 & -0.005 & -0.007 & -0. \\
\hline & $(0.0$ & $(0.008$ & & & & & & $(0$. & $(0.007)$ & \\
\hline \multirow[t]{2}{*}{ EU } & -0.01 & 0.080 & 0.2 & 0.3 & $* * *$ & 0.4 & $0.504 * * *$ & $0.639 * * *$ & $0.647 * * *$ & 0. \\
\hline & $(0.2$ & $(0.201)$ & $(0.1$ & $(0.127)$ & $(0.117)$ & $(0.1$ & $(0.151)$ & $(0.152)$ & $(0.171)$ & \\
\hline \multirow[t]{2}{*}{ RTEC } & $-0.060 * * *$ & $-0.061 * * *$ & $-0.064 * * *$ & $-0.063 * * *$ & $-0.064 * * *$ & $-0.065 * * *$ & $-0.065 * * *$ & $-0.061 * * *$ & $-0.063 * * *$ & $-0.067 * * *$ \\
\hline & $(0.0$ & $(0.000$ & $(0$. & $(0.0$ & & $(0$. & $(0$. & $(0)$. & $(0.005)$ & \\
\hline \multirow[t]{2}{*}{$\alpha_{0}$} & -53.1 & $-53.83 * * *$ & -49.8 & $-49.81 * * *$ & $k * *$ & -46. & $7 * * *$ & $-44.73 * * *$ & $-41.36 * * *$ & $-36.56 * * *$ \\
\hline & $(6.602)$ & $(6.048)$ & $(5.067)$ & $(3.830)$ & $(3.521)$ & $(3.596)$ & $(4.526)$ & $(4.565)$ & $(5.133)$ & $(10.33)$ \\
\hline
\end{tabular}

These results partially contradict the findings reported by Albulescu et al. (2020), who documented a significant role of EU environmental regulations in carbon emissions decreasing, but no significant effects for the entry into force of the Kyoto protocol. The discrepancies might be explained by the fact that the Kyoto protocol has not determined an abrupt decline in $\mathrm{CO}_{2}$ 
emissions and the dummy variable used in Albulescu et al. (2020) was not efficient in this case. Moreover, the country sample was different. However, in line with this study, we confirmed the EKC hypothesis and the role of renewables for reducing carbon emissions.

\subsection{A focus on the EU situation}

To get further insight into the role of environmental regulations on carbon emissions, we focused on EU countries (Table 5). Our sample included 18 EU countries with different levels of economic development and energy consumption. These findings are very similar to those reported in Table 2, proving their robustness. However, the EKC hypothesis was only documented for the middle quantiles in this case. In addition, for the EU countries, the effect of environmental policy stringency was higher for the upper quantiles associated with higher polluters. A similar robustness check was conducted for the OECD countries sample (Table A3 - Appendix) and confirmed the main results.

Table 5. Panel conditional quantile regression-EU countries sample

\begin{tabular}{|c|c|c|c|c|c|c|c|c|c|c|}
\hline \multirow{2}{*}{ Quantiles } & \multicolumn{3}{|c|}{ Lower } & \multicolumn{4}{|c|}{ Middle } & \multicolumn{3}{|c|}{ Upper } \\
\hline & 0.05 & 0.15 & 0.25 & 0.35 & 0.45 & 0.55 & 0.65 & 0.75 & 0.85 & 0.95 \\
\hline \multirow[t]{2}{*}{ EPSI } & $-0.261 * * *$ & $-0.264 * * *$ & $-0.189 * * *$ & $-0.231 * * *$ & $-0.239 * * *$ & $-0.269 * * *$ & $-0.294 * * *$ & $-0.302 * * *$ & $-0.307 * * *$ & $-0.238 * * *$ \\
\hline & $(0.075)$ & $(0.059)$ & $(0.046)$ & $(0.036)$ & $(0.039)$ & $(0.040)$ & $(0.039)$ & $(0.045)$ & $(0.056)$ & $(0.086)$ \\
\hline \multirow[t]{2}{*}{ GDP } & 0.977 & 3.241 & 3.739 & $4.390 * *$ & $4.665 * *$ & 3.132 & $3.860 *$ & 2.976 & 3.338 & -3.101 \\
\hline & $(4.282)$ & $(3.348)$ & $(2.618)$ & $(2.044)$ & $(2.227)$ & $(2.289)$ & $(2.223)$ & $(2.581)$ & $(3.193)$ & $(4.871)$ \\
\hline \multirow[t]{2}{*}{$\mathrm{GDP}^{2}$} & -0.055 & -0.169 & -0.199 & $-0.228 * *$ & $-0.241 * *$ & -0.161 & $-0.196^{*}$ & -0.151 & -0.167 & 0.161 \\
\hline & $(0.215)$ & $(0.168)$ & $(0.131)$ & $(0.103)$ & $(0.112)$ & $(0.115)$ & $(0.112)$ & $(0.130)$ & $(0.160)$ & $(0.245)$ \\
\hline \multirow[t]{2}{*}{ FDI } & -0.005 & -0.006 & $-0.009 * *$ & -0.003 & -0.004 & -0.004 & -0.005 & -0.006 & $-0.008^{*}$ & -0.010 \\
\hline & $(0.007)$ & $(0.005)$ & $(0.004)$ & $(0.003)$ & $(0.004)$ & $(0.004)$ & $(0.004)$ & $(0.004)$ & $(0.005)$ & $(0.008)$ \\
\hline \multirow[t]{2}{*}{ EU } & $3.772 * * *$ & $3.917 * * *$ & $4.219 * * *$ & $4.140 * * *$ & $4.190 * * *$ & $4.033 * * *$ & $4.099 * * *$ & $4.238 * * *$ & $4.255^{* * *}$ & $4.406 * * *$ \\
\hline & $(0.235)$ & $(0.184)$ & $(0.144)$ & $(0.112)$ & $(0.122)$ & $(0.126)$ & $(0.122)$ & $(0.142)$ & $(0.175)$ & $(0.267)$ \\
\hline \multirow[t]{2}{*}{ RTEC } & $-0.123 * * *$ & $-0.118 * * *$ & $-0.117 * * *$ & $-0.114 * * *$ & $-0.112 * * *$ & $-0.107 * * *$ & $-0.106 * * *$ & $-0.103 * * *$ & $-0.103 * * *$ & $-0.094 * * *$ \\
\hline & $(0.006)$ & $(0.005)$ & $(0.004)$ & $(0.003)$ & $(0.003)$ & $(0.003)$ & $(0.003)$ & $(0.003)$ & $(0.004)$ & $(0.007)$ \\
\hline \multirow[t]{2}{*}{$\alpha_{0}$} & -25.61 & $-37.73 * *$ & $-42.09 * * *$ & $-44.96 * * *$ & $-46.73 * * *$ & $-38.00 * * *$ & $-42.15 * * *$ & $-38.84 * * *$ & $-40.88 * *$ & -10.56 \\
\hline & $(21.70)$ & $(16.97)$ & $(13.27)$ & $(10.36)$ & $(11.28)$ & (11.60) & $(11.27)$ & $(13.08)$ & $(16.18)$ & $(24.69)$ \\
\hline
\end{tabular}

The last set of estimations compared the two EU countries subsamples: not at risk and at risk of achieving the 20-20-20 target in terms of GHG emissions. It is expected that countries with a higher risk of missing the targets will enhance policy stringency in order to achieve the targets for 2020. Indeed, if we compare the results from Tables 6 and 7, we observe that EPSI had a negative impact on $\mathrm{CO}_{2}$ emissions in both cases, whereas the effect was stronger for the countries at risk of achieving the targets. There is mixed evidence regarding the EKC hypothesis, while the FDI impact was insignificant. For both samples, energy use played a 

emissions.

Table 6. Panel conditional quantile regression-EU countries sample not at risk of achieving the 20-20-20 target in terms of GHG emissions, as projected in 2016

\begin{tabular}{|c|c|c|c|c|c|c|c|c|c|c|}
\hline \multirow[t]{2}{*}{ Quantiles } & \multicolumn{3}{|c|}{ Lower } & \multicolumn{4}{|c|}{ Middle } & \multicolumn{3}{|c|}{ Upper } \\
\hline & 0.05 & 0.15 & 0.25 & 0.35 & 0.45 & 0.55 & 0.65 & 0.75 & 0.85 & 0.95 \\
\hline \multirow[t]{2}{*}{ EPSI } & $-0.303 * * *$ & $-0.241 * * *$ & $-0.194 * * *$ & $-0.176 * * *$ & $-0.173 * * *$ & $-0.187 * * *$ & $-0.208 * * *$ & $-0.195 * * *$ & $-0.140 * *$ & -0.098 \\
\hline & $(0.073)$ & $(0.071)$ & $(0.052)$ & $(0.040)$ & $(0.038)$ & $(0.039)$ & $(0.039)$ & $(0.048)$ & $(0.058)$ & $(0.084)$ \\
\hline \multirow[t]{2}{*}{ GDP } & $-7.974^{*}$ & -3.111 & 1.261 & 1.494 & $4.036^{*}$ & $4.450^{*}$ & $5.121 * *$ & $6.959 * *$ & 7.097* & $9.542^{*}$ \\
\hline & $(4.631)$ & $(4.519)$ & $(3.322)$ & $(2.536)$ & $(2.400)$ & $(2.517)$ & $(2.501)$ & $(3.075)$ & $(3.676)$ & $(5.385)$ \\
\hline \multirow[t]{2}{*}{$\mathrm{GDP}^{2}$} & 0.379 & 0.129 & -0.102 & -0.113 & $-0.238^{*}$ & $-0.259 * *$ & $-0.294 * *$ & $-0.388 * *$ & $-0.397 * *$ & $-0.523^{*}$ \\
\hline & $(0.235)$ & $(0.229)$ & $(0.168)$ & $(0.129)$ & $(0.122)$ & $(0.128)$ & $(0.127)$ & $(0.156)$ & $(0.186)$ & $(0.273)$ \\
\hline \multirow[t]{2}{*}{ FDI } & 0.004 & 0.001 & -0.001 & -0.002 & -0.003 & -0.004 & -0.005 & -0.006 & -0.008 & -0.009 \\
\hline & $(0.007)$ & $(0.007)$ & $(0.005)$ & $(0.004)$ & $(0.004)$ & $(0.004)$ & $(0.004)$ & $(0.005)$ & $(0.006)$ & $(0.008)$ \\
\hline \multirow[t]{2}{*}{ EU } & $3.511 * * *$ & $3.707 * * *$ & $4.073 * * *$ & $4.105 * * *$ & $4.029 * * *$ & $4.043 * * *$ & $4.060 * * *$ & $4.133 * * *$ & $4.352 * * *$ & $4.751 * * *$ \\
\hline & $(0.239)$ & $(0.233)$ & $(0.171)$ & $(0.131)$ & $(0.124)$ & $(0.130)$ & $(0.129)$ & $(0.158)$ & $(0.189)$ & $(0.278)$ \\
\hline \multirow[t]{2}{*}{ RTEC } & $-0.084 * * *$ & $-0.085 * * *$ & $-0.082 * * *$ & $-0.082 * * *$ & $-0.079 * * *$ & $-0.075 * * *$ & $-0.072 * * *$ & $-0.067 * * *$ & $-0.065 * * *$ & $-0.056 * * *$ \\
\hline & $(0.005)$ & $(0.005)$ & $(0.004)$ & $(0.003)$ & $(0.003)$ & $(0.003)$ & $(0.003)$ & (0.004) & $(0.004)$ & $(0.006)$ \\
\hline \multirow[t]{2}{*}{$\alpha_{0}$} & 21.92 & -3.020 & -26.434 & $-27.88 * *$ & $-40.00 * * *$ & $-42.15 * * *$ & $-45.36 * * *$ & $-54.86 * * *$ & $-57.01 * * *$ & $-72.03 * * *$ \\
\hline & (23.62) & (23.05) & (16.94) & $(12.93)$ & $(12.24)$ & $(12.84)$ & $(12.75)$ & $(15.68)$ & $(18.75)$ & $(27.47)$ \\
\hline
\end{tabular}

Table 7. Panel conditional quantile regression-EU countries sample at risk of achieving the 20-20-20 target in terms of GHG emissions, as projected in 2016

\begin{tabular}{|c|c|c|c|c|c|c|c|c|c|c|}
\hline \multirow[t]{2}{*}{ Quantiles } & \multicolumn{3}{|c|}{ Lower } & \multicolumn{4}{|c|}{ Middle } & \multicolumn{3}{|c|}{ Upper } \\
\hline & 0.05 & 0.15 & 0.25 & 0.35 & 0.45 & 0.55 & 0.65 & 0.75 & 0.85 & 0.95 \\
\hline \multirow[t]{2}{*}{ EPSI } & $-0.339 * *$ & $-0.444 *$ & $-0.597 * * *$ & $-0.647 * * *$ & $-0.620 * * *$ & $-0.613 * * *$ & $-0.579 * * *$ & $-0.466 * * *$ & -0.358 & -0.647 \\
\hline & $(0.145)$ & $(0.234)$ & $(0.149)$ & $(0.129)$ & $(0.126)$ & $(0.158)$ & $(0.176)$ & $(0.176)$ & $(0.266)$ & $(0.596)$ \\
\hline \multirow[t]{2}{*}{ GDP } & 1.119 & $87.51 *$ & $75.84 * * *$ & $66.36 * * *$ & $77.79 * * *$ & $63.27 * *$ & $62.69 *$ & $69.65 * *$ & 69.61 & 34.68 \\
\hline & $(27.91)$ & $(45.25)$ & $(28.68)$ & $(25.00)$ & $(24.27)$ & $(30.57)$ & $(33.97)$ & $(33.92)$ & $(51.43)$ & $(115.1)$ \\
\hline \multirow[t]{2}{*}{$\mathrm{GDP}^{2}$} & -0.109 & $-4.165 *$ & $-3.594 * * *$ & $-3.141 * * *$ & $-3.679 * * *$ & $-2.990 * *$ & $-2.966^{*}$ & $-3.284 * *$ & -3.285 & -1.555 \\
\hline & $(1.322)$ & $(2.143)$ & $(1.358)$ & $(1.184)$ & $(1.150)$ & $(1.448)$ & $(1.609)$ & $(1.606)$ & $(2.436)$ & $(5.451)$ \\
\hline \multirow[t]{2}{*}{ FDI } & -0.000 & -0.017 & $-0.017 * *$ & $-0.013 * *$ & $-0.011 *$ & -0.010 & -0.006 & -0.012 & $-0.022 *$ & -0.031 \\
\hline & $(0.007)$ & $(0.011)$ & $(0.007)$ & $(0.0$ & $(0.4$ & $(0)$. & $(0.4$ & $(0.008)$ & $(0.012)$ & $(0.028)$ \\
\hline \multirow[t]{2}{*}{$\mathrm{EU}$} & $7.458 * * *$ & $6.805^{* * *}$ & $7.073 * * *$ & $7.201 * * *$ & $7.045^{* * *}$ & $7.079 * * *$ & $7.043 * * *$ & $7.102 * * *$ & $7.658 * * *$ & $7.850 * * *$ \\
\hline & $(0.387)$ & $(0.627)$ & $(0.397)$ & $(0.346)$ & $(0.336)$ & $(0.423)$ & $(0.470)$ & $(0.470)$ & $(0.712)$ & (1.594) \\
\hline \multirow[t]{2}{*}{ RTEC } & $-0.121 * * *$ & $-0.133 * * *$ & $-0.124 * * *$ & $-0.121 * * *$ & $-0.115 * * *$ & $-0.113 * * *$ & $-0.111 * * *$ & $-0.124 * * *$ & $-0.134 * * *$ & $-0.127 * * *$ \\
\hline & $(0.010)$ & $(0.015)$ & $(0.010)$ & $(0.009)$ & $(0.008)$ & $(0.010)$ & $(0.012)$ & $(0.012)$ & $(0.018)$ & $(0.039)$ \\
\hline \multirow[t]{2}{*}{$\alpha_{0}$} & -50.56 & $-504.1 * *$ & $-446.6 * * *$ & $-397.9 * * *$ & $-457.2 * * *$ & $-381.1 * *$ & $-377.4 * *$ & $-415.7 * *$ & -419.6 & -244.6 \\
\hline & (145.5) & (235.9) & (149.5) & (130.4) & $(126.6)$ & (159.4) & \begin{tabular}{|l|}
$(177.1)$ \\
\end{tabular} & (176.9) & $(268.2)$ & $(600.2)$ \\
\hline
\end{tabular}

\section{Conclusions and policy implications}

Environmental degradation requires immediate action. Actions can be grouped into two main categories, namely green innovation and adequate environmental regulations and climate policies necessary to reduce pollution levels. 
Most of the existing empirical works have focused on air pollution and the role of environmental regulations, such as standards, taxes or penalties. However, only a few works have addressed the effectiveness of environmental regulations, with mixed findings. A focus on the impact of policy stringency is almost non-existent. In this context, our paper contributes to the literature by assessing the asymmetric and non-linear impact of environmental policy stringency on $\mathrm{CO}_{2}$ emissions in a set of OECD countries. To this end, we rely on Canay's (2011) panel regression in quantiles.

Our main findings show that environmental policy stringency has led to a decrease in $\mathrm{CO}_{2}$ emissions in OECD countries. However, as expected, this effect has been asymmetric. Likewise, we show that EPSI has a stronger impact on emissions in countries with lower levels of carbon emissions (that is, at lower quantiles). We also document the importance of energy use and revenue on $\mathrm{CO}_{2}$ emissions levels. However, our findings invalidate the $\mathrm{PHH}$ and show that the impact of the share of renewables in the total electricity consumption has only a marginal negative impact on emissions.

The robustness check we performed for a set of 18 EU countries validated the main findings of the paper. Further, additional tests indicated that EPSI negatively impacts the emissions level only during the implementation of the Kyoto protocol, whereas in the pre-Kyoto period, the environmental regulations were completely inefficient. Moreover, policy stringency measures are more effective in EU countries at higher risk of missing the 20-20-20 target in terms of GHG emissions.

Our findings have different implications for policymakers. First, policy stringency measures should be correlated with emissions levels to become effective. EU countries have succeeded in lowering air pollution levels by imposing higher levels of stringency and clear emission targets. If the risk of missing the target is high, environmental policy stringency should increase. Second, in order to record a negative trend in carbon emissions on a global level, emerging economies should follow the EU model. Energy consumption still represents the main driver of emissions, whereas the use of renewables has only a marginal effect on air pollution levels.

The limitation of this papers resides in the data availability, which did not allow us to investigate the recent period. However, the analysis can be developed by making a comparison between market-based and non-market-based policies or by assessing the effectiveness of specific regulations used for environmental protection. 


\section{Acknowledgements}

This work was supported by a Grant of the Romanian National Authority for Scientific Research and Innovation, CNCS-UEFISCDI, Project Number PN-III-P1-1.1-TE-2019-0436.

\section{References}

Adedoyin FF, Gumede MI, Bekun FV, Etokakpan MU, Balsalobre-Lorente D (2020) Modelling coal rent, economic growth and $\mathrm{CO}_{2}$ emissions: Does regulatory quality matter in BRICS economies? Science of the Total Environment 710:136284.

Ahmed K (2020) Environmental policy stringency, related technological change and emissions inventory in 20 OECD countries. Journal of Environmental Management 274:111209.

Ahmed K, Ahmed S (2018) A predictive analysis of $\mathrm{CO}_{2}$ emissions, environmental policy stringency, and economic growth in China. Environmental Science and Pollution Research 25(16):16091-16100.

Albulescu CT, Artene AE, Luminosu CT, Tamasila M (2020) $\mathrm{CO}_{2}$ emissions, renewable energy production and environmental regulation in the EU countries. Environmental Science and Pollution Research 27:33615-33635.

Albulescu CT, Kang SH, Tiwari AK, Yoon S-M (2019) FDI, income, and environmental pollution in Latin America: Replication and extension using panel quantiles regression analysis. Energy Economics 84:104504.

Aliprand, F, Stoppato A, Mirandola A (2016) Estimating $\mathrm{CO}_{2}$ emissions reduction from renewable energy use in Italy. Renewable Energy 96:220-232.

Álvarez-Herránz A, Balsalobre D, Cantos JM, Shahbaz M (2017) Energy innovations-GHG emissions nexus: Fresh empirical evidence from OECD countries. Energy Policy 101:90100 .

Apergis N, Ozturk I (2015) Testing environmental Kuznets curve hypothesis in Asian countries. Ecological Indicators 52:16-22.

Asafu-Adjaye J, Mahadevan R (2013) Implications of $\mathrm{CO}_{2}$ reduction policies for a high carbon emitting economy. Energy Economics 38:32-41.

Benvenutti LM, Uriona-Maldonado M, Campos LM (2019) The impact of $\mathrm{CO}_{2}$ mitigation policies on light vehicle fleet in Brazil. Energy Policy 126:370-379.

Botta E, Koźluk T (2014) Measuring environmental policy stringency in OECD countries: A composite index approach. OECD Economics Department Working Papers No. 1177. https://doi.org/10.1787/5jxrjnc45gvg-en. 
Boyd R, Krutilla K, Viscusi WK (1995) Energy taxation as a policy instrument to reduce $\mathrm{CO}_{2}$ emissions: A net benefit analysis. Journal of Environmental Economics and Management 29(1):1-24.

Canay IA (2011) A simple approach to quantile regression for panel data. Econometrics Journal 14:368-386.

Chen Y, Wang Z, Zhong Z (2019) $\mathrm{CO}_{2}$ emissions, economic growth, renewable and nonrenewable energy production and foreign trade in China. Renewable Energy 131:208216.

Cheng Z, Li L, Liu J (2017) The emissions reduction effect and technical progress effect of environmental regulation policy tools. Journal of Cleaner Production 149:191-205.

De Angelis EM, Di Giacomo M, Vannoni D (2019) Climate change and economic growth: The role of environmental policy stringency. Sustainability 11(8):2273.

Dong K, Hochman G, Zhang Y, Sun R, Li H, Liao H (2018) $\mathrm{CO}_{2}$ emissions, economic and population growth, and renewable energy: Empirical evidence across regions. Energy Economics 75:180-192.

Galeotti M, Salini S, Verdolini E (2020) Measuring environmental policy stringency: Approaches, validity, and impact on environmental innovation and energy efficiency. Energy Policy 136:111052.

Galvao Jr., AF (2011) Quantile regression for dynamic panel data with fixed effects. Journal of Econometrics 164:142-157.

Hashmi R, Alam K (2019) Dynamic relationship among environmental regulation, innovation, $\mathrm{CO}_{2}$ emissions, population, and economic growth in OECD countries: A panel investigation. Journal of Cleaner Production 231:1100-1109.

Huo J, Yang D, Zhang W, Wang F, Wang G, Fu Q (2015) Analysis of influencing factors of $\mathrm{CO}_{2}$ emissions in Xinjiang under the context of different policies. Environmental Science \& Policy 45:20-29.

IEA (2019) $\mathrm{CO}_{2}$ emissions from fuel combustion: Overview. An essential tool for analysts and policy makers. Statistics report — July 2020. https://www.iea.org/reports/co2-emissionsfrom-fuel-combustion-overview. Accessed 10 February 2021.

Inglesi-Lotz R, Dogan E (2018) The role of renewable versus nonrenewable energy to the level of $\mathrm{CO}_{2}$ emissions a panel analysis of sub-Saharan Africa's big 10 electricity generators. Renewable Energy 123:36-43. 
Johnstone N, Haščič I, Poirier J, Hemar M, Michel C (2012) Environmental policy stringency and technological innovation: Evidence from survey data and patent counts. Applied Economics 44(17):2157-2170.

Koenker R (2004) Quantile regression for longitudinal data. Journal of Multivariate Analysis 91(1): 9174-9189.

Koźluk T, Zipperer V (2015) Environmental policies and productivity growth: A critical review of empirical findings. OECD Journal: Economic Studies 2014(1):155-185. https://doi.org/10.1787/eco_studies-2014-5jz2drqm175j

Lamarche C (2010) Robust penalized quantile regression estimation for panel data. Journal of Econometrics 157:396-408.

Li M, Mi Z, Coffman DM, Wei YM (2018) Assessing the policy impacts on non-ferrous metals industry's $\mathrm{CO}_{2}$ reduction: Evidence from China. Journal of Cleaner Production 192:252261.

Li X, Qiao Y, Shi L (2017) The aggregate effect of air pollution regulation on $\mathrm{CO}_{2}$ mitigation in China's manufacturing industry: An econometric analysis. Journal of Cleaner Production 142:976-984.

Ma D, Fei R, Yu Y (2018) How government regulation impacts on energy and $\mathrm{CO}_{2}$ emissions performance in China's mining industry. Resources Policy 62:651-663.

Machiba T (2010) Eco-innovation for enabling resource efficiency and green growth: Development of an analytical framework and preliminary analysis of industry and policy practices. International Economics and Economic Policy 7:357-370.

Mao X, Yang S, Liu Q, Tu J, Jaccard M (2012) Achieving $\mathrm{CO}_{2}$ emission reduction and the cobenefits of local air pollution abatement in the transportation sector of China. Environmental Science \& Policy 21:1-13.

Mardones C, Flores B (2018) Effectiveness of a $\mathrm{CO}_{2}$ tax on industrial emissions. Energy Economics 71:370-382.

Martínez-Zarzoso I, Bengochea-Morancho A, Morales-Lage R (2019) Does environmental policy stringency foster innovation and productivity in OECD countries? Energy Policy 134:110982.

Niedertscheider M, Haas W, Göthe C (2018) Austrian climate policies and GHG-emissions since 1990: What is the role of climate policy integration? Environmental Science \& Policy 81:10-17. 
Ouyang X, Shao Q, Zhu H, He H, Xiang C, Wei G (2019) Environmental regulation, economic growth and air pollution: Panel threshold analysis for OECD countries. Science of The Total Environment 657:234-241.

Pao HT, Yu HC, Yang YH (2011) Modeling the $\mathrm{CO}_{2}$ emissions, energy use, and economic growth in Russia. Energy 36(8):5094-5100.

Rosen AM (2012) Set identification via quantile restrictions in short panels. Journal of Econometrics 166:127-137.

Sadik-Zada ER, Ferrari M (2020) Environmental policy stringency, technical progress and pollution haven hypothesis. Sustainability 12(9):3880.

Sapkota P, Bastola U (2017) Foreign direct investment, income, and environmental pollution in developing countries: Panel data analysis of Latin America. Energy Economics 64:206-212.

Simões S, Cleto J, Fortes P, Seixas J, Huppes G (2008) Cost of energy and environmental policy in Portuguese $\mathrm{CO}_{2}$ abatement—scenario analysis to 2020. Energy Policy 36(9):35983611.

Sinha A, Shahbaz M (2018) Estimation of environmental Kuznets Curve for $\mathrm{CO}_{2}$ emission: Role of renewable energy generation in India. Renew Energy 119:703-711.

Wang K, Yan M, Wang Y, Chang CP (2020a) The impact of environmental policy stringency on air quality. Atmospheric Environment 231:117522.

Wang Y, Sun X, Wang B, Liu X (2020b) Energy saving, GHG abatement and industrial growth in OECD countries: A green productivity approach. Energy 194:116833.

Wenbo G, Yan C (2018) Assessing the efficiency of China's environmental regulation on carbon emissions based on Tapio decoupling models and GMM models. Energy Reports $4: 713-723$.

Wolde-Rufael Y, Mulat-Weldemeskel E (2021) Do environmental taxes and environmental stringency policies reduce $\mathrm{CO}_{2}$ emissions? Evidence from 7 emerging economies. Environmental Science and Pollution Research 28:22392-22408.

$\mathrm{Xu}$ X, Xu X, Chen Q, Che Y (2018) The impacts on $\mathrm{CO}_{2}$ emission reduction and haze by coal resource tax reform based on dynamic CGE model. Resources Policy 58:268-276.

Yahoo M, Othman J (2017) Employing a CGE model in analyzing the environmental and economy-wide impacts of $\mathrm{CO}_{2}$ emission abatement policies in Malaysia. Science of the Total Environment 584:234-243.

Yin J, Zheng M, Chen J (2015) The effects of environmental regulation and technical progress on $\mathrm{CO}_{2}$ Kuznets curve: An evidence from China. Energy Policy 77:97-108. 


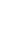

Zhao X, Yin H, Zhao Y (2015) Impact of environmental regulations on the efficiency and $\mathrm{CO}_{2}$ emissions of power plants in China. Applied Energy 149:238-247.

Zoundi $\mathrm{Z}$ (2017) $\mathrm{CO}_{2}$ emissions, renewable energy and the environmental Kuznets Curve, a panel cointegration approach. Renewable \& Sustainable Energy Reviews 72:1067-1075. *** https://ec.europa.eu/clima/policies/strategies/progress_en

*** https://www.oecd.org/environment/how-stringent-are-environmental-policies.htm

*** https://www.eea.europa.eu/themes/climate/trends-and-projections-in-europe/trends-andprojections-in-europe-2016/1-overall-progress-towards-the

*** https://www.oecd.org/economy/greeneco/how-stringent-are-environmental-policies.htm 
601 Table A1. Environmental policies and regulations and $\mathrm{CO}_{2}$ emissions: a recent comparative

literature review

\begin{tabular}{|c|c|c|c|c|}
\hline Study & Country/area & Period & Methodology & Results \\
\hline $\begin{array}{l}\text { Ahmed } \\
(2020)\end{array}$ & $\begin{array}{l}20 \text { OECD } \\
\text { countries }\end{array}$ & $\begin{array}{l}1999- \\
2015\end{array}$ & $\begin{array}{l}\text { Panel Auto Regressive. } \\
\text { Distributed Lag (PARDL), } \\
\text { PMG and Error Correction } \\
\text { Models (ECM) }\end{array}$ & $\begin{array}{l}\text { Stringent environmental policies } \\
\text { promote green innovation. } \\
\text { Stricter policies are subject to } \\
\text { negative economic shock in the } \\
\text { short run. }\end{array}$ \\
\hline $\begin{array}{l}\text { Albulescu et } \\
\text { al. }(2020)\end{array}$ & $\begin{array}{l}12 \mathrm{EU} \\
\text { countries }\end{array}$ & $\begin{array}{l}1990- \\
2017\end{array}$ & $\begin{array}{l}\text { Static panel data models } \\
\text { and dynamic GMM } \\
\text { models }\end{array}$ & $\begin{array}{l}\text { Mixed evidence on the role of } \\
\text { environmental regulations in } \\
\text { influencing the reduction of } \mathrm{CO}_{2} \\
\text { emissions in EU countries }\end{array}$ \\
\hline $\begin{array}{l}\text { Galeotti et al. } \\
(2020)\end{array}$ & $\begin{array}{l}19 \text { OECD } \\
\text { countries }\end{array}$ & $\begin{array}{l}1995- \\
2009\end{array}$ & $\begin{array}{l}\text { Computing different } \\
\text { indicators of } \\
\text { environmental policy } \\
\text { stringency }\end{array}$ & $\begin{array}{l}\text { Indicators based on pollution } \\
\text { abatement give rise to } \\
\text { significantly different results } \\
\text { than emission-based indicators or } \\
\text { composite indexes. }\end{array}$ \\
\hline $\begin{array}{l}\text { Hashmi and } \\
\text { Alam (2019) }\end{array}$ & $\begin{array}{l}29 \text { OECD } \\
\text { countries }\end{array}$ & $\begin{array}{l}1999- \\
2014\end{array}$ & $\begin{array}{l}\text { Stochastic impacts by } \\
\text { regression on population, } \\
\text { affluence, regulation and } \\
\text { technology (STIRPART) } \\
\text { framework, GMM models }\end{array}$ & $\begin{array}{l}\text { An increase in environmentally } \\
\text { friendly patents and in } \\
\text { environmental tax revenue per } \\
\text { capita reduces carbon emissions. }\end{array}$ \\
\hline $\begin{array}{l}\text { Johnstone et } \\
\text { al. (2012) }\end{array}$ & 77 countries & $\begin{array}{l}2001- \\
2007\end{array}$ & $\begin{array}{l}\text { Panel data, two-stage } \\
\text { models }\end{array}$ & $\begin{array}{l}\text { Positive role of both general } \\
\text { innovative } \text { capacity } \\
\text { environmental policy stringency } \\
\text { on } \\
\text { innovation. }\end{array}$ \\
\hline $\begin{array}{l}\text { Ouyang et al. } \\
(2019)\end{array}$ & $\begin{array}{l}30 \text { OECD } \\
\text { countries }\end{array}$ & $\begin{array}{l}1998- \\
2015\end{array}$ & $\begin{array}{l}\text { Panel threshold model to } \\
\text { explore the non-linear } \\
\text { effects of environmental } \\
\text { regulations on PM } 2.5 \\
\text { pollutions }\end{array}$ & $\begin{array}{l}\text { This study has revealed the } \\
\text { existence of an inverted U- } \\
\text { shaped relationship between } \\
\text { environmental regulations and } \\
\text { PM2.5 emissions. }\end{array}$ \\
\hline $\begin{array}{l}\text { Sadik-Zada, } \\
\text { and Ferrari } \\
(2020)\end{array}$ & $\begin{array}{l}26 \text { OECD } \\
\text { countries }\end{array}$ & $\begin{array}{l}1995- \\
2011\end{array}$ & $\begin{array}{l}\text { Variational model of } \\
\text { environmental } \\
\text { degradation, pooled mean } \\
\text { group (PMG) estimator }\end{array}$ & $\begin{array}{l}\text { Different thresholds of } \\
\text { environmental degradation, } \\
\text { strong and robust confirmation of } \\
\text { the pollution haven conjecture }\end{array}$ \\
\hline $\begin{array}{l}\text { Wang et al. } \\
(2020 \mathrm{a})\end{array}$ & $\begin{array}{l}25 \text { OECD } \\
\text { countries }\end{array}$ & $\begin{array}{l}1990- \\
2015\end{array}$ & $\begin{array}{l}\text { Panel data, system } \\
\text { generalised moments } \\
\text { (SYS-GMM) }\end{array}$ & $\begin{array}{l}\text { Environmental policy strictness } \\
\text { has a significant effect on } \mathrm{CO}_{2} \text {, } \\
\mathrm{NO}_{\mathrm{x}} \text {, and } \mathrm{SO}_{\mathrm{x}} \text { emissions, } \\
\text { whereas the impact on PM } 2.5 \\
\text { emissions and PM } 2.5 \text { exposure is } \\
\text { very weak. }\end{array}$ \\
\hline $\begin{array}{l}\text { Wolde- } \\
\text { Rufael and } \\
\text { Mulat- } \\
\text { Weldemeskel } \\
\text { (2021) }\end{array}$ & $\begin{array}{l}\text { Czech } \\
\text { Republic, } \\
\text { Greece, } \\
\text { Hungary, } \\
\text { Korea, } \\
\text { Poland, } \\
\text { South Africa, } \\
\text { and Turkey }\end{array}$ & $\begin{array}{l}1994- \\
2015\end{array}$ & $\begin{array}{l}\text { Panel data, augmented } \\
\text { mean group (AMG) } \\
\text { estimator }\end{array}$ & $\begin{array}{l}\text { Inverted } \mathrm{U} \text {-shaped relationship } \\
\text { between } \mathrm{CO}_{2} \text { emissions and } \\
\text { environmental policy stringency }\end{array}$ \\
\hline
\end{tabular}


Table A2. Country sample-OECD statistics

\begin{tabular}{lccc}
\hline Country & $\begin{array}{c}\text { OECD } \\
\text { member }\end{array}$ & $\begin{array}{c}\text { EU } \\
\text { member* }\end{array}$ & $\begin{array}{c}\text { Emerging } \\
\text { economy }\end{array}$ \\
\hline Australia & $\mathrm{X}$ & & \\
Austria & $\mathrm{X}$ & $\mathrm{X}^{*}$ & \\
Belgium & $\mathrm{X}$ & $\mathrm{X}^{*}$ & \\
Brazil & & & $\mathrm{X}$ \\
Canada & $\mathrm{X}$ & & $\mathrm{X}$ \\
China & & & \\
Czech Republic & $\mathrm{X}$ & $\mathrm{X}$ & \\
Denmark & $\mathrm{X}$ & $\mathrm{X}^{*}$ & \\
Finland & $\mathrm{X}$ & $\mathrm{X}$ & \\
France & $\mathrm{X}$ & $\mathrm{X}$ & \\
Germany & $\mathrm{X}$ & $\mathrm{X}$ & \\
Greece & $\mathrm{X}$ & $\mathrm{X}$ & \\
Hungary & $\mathrm{X}$ & $\mathrm{X}$ & \\
India & & & $\mathrm{X}$ \\
Indonesia & & & $\mathrm{X}$ \\
Ireland & $\mathrm{X}$ & $\mathrm{X}$ & \\
Italy & $\mathrm{X}$ & $\mathrm{X}$ & \\
Japan & $\mathrm{X}$ & & \\
Korea & $\mathrm{X}$ & & \\
Netherlands & $\mathrm{X}$ & $\mathrm{X}$ & \\
Norway & $\mathrm{X}$ & & \\
Poland & $\mathrm{X}$ & $\mathrm{X}$ & \\
Portugal & $\mathrm{X}$ & $\mathrm{X}$ & \\
Russia & $\mathrm{X}$ & $\mathrm{X}$ & \\
Slovak Republic & $\mathrm{X}$ & $\mathrm{X}$ & \\
South Africa & $\mathrm{X}$ & $\mathrm{X}$ & \\
Spain & $\mathrm{X}$ & & \\
Sweden & & & \\
Switzerland & $\mathrm{X}$ & \\
Turkey & & & \\
United Kingdom** & & \\
United States & X & \\
\hline Notes: * The EU 20-20-20 GHC emission \\
projected in 2015 (https://www.eea.europa.eu/thet at risk of not being achieved, as \\
in-europe/ trends-and-projections-in-europe-2016/1-overall-progress-towards-the); ** \\
As of 1 January 2021, the United Kingdom has left the EU. & \\
\hline
\end{tabular}


615 Table A3. Panel conditional quantile regression-OECD countries sample

\begin{tabular}{|c|c|c|c|c|c|c|c|c|c|c|}
\hline \multirow[t]{2}{*}{ Quantiles } & \multicolumn{3}{|c|}{ Lower } & \multicolumn{4}{|c|}{ Middle } & \multicolumn{3}{|c|}{ Upper } \\
\hline & 0.05 & 0.15 & 0.25 & 0.35 & 0.45 & 0.55 & 0.65 & 0.75 & 0.85 & 0.95 \\
\hline \multirow[t]{2}{*}{ EPSI } & $-0.162 * *$ & $-0.183 * * *$ & $-0.128 * * *$ & $-0.120 * * *$ & $-0.123 * * *$ & $-0.096 * * *$ & $-0.091 * * *$ & -0.054 & -0.057 & 0.144 \\
\hline & $(0.076)$ & $(0.062)$ & $(0.043)$ & $(0.029)$ & $(0.028)$ & $(0.032)$ & $(0.035)$ & $(0.038)$ & $(0.049)$ & $(0.106)$ \\
\hline \multirow[t]{2}{*}{ GDP } & 5.773 & -0.196 & -1.931 & -1.720 & -0.842 & -0.792 & -0.312 & -0.908 & -2.037 & -6.224 \\
\hline & $(3.754)$ & $(3.042)$ & $(2.122)$ & $(1.420)$ & $(1.383)$ & $(1.575)$ & $(1.728)$ & $(1.848)$ & $(2.402)$ & $(5.198)$ \\
\hline \multirow[t]{2}{*}{$\mathrm{GDP}^{2}$} & $-0.319 *$ & -0.021 & 0.066 & 0.053 & 0.008 & 0.006 & -0.021 & 0.009 & 0.070 & 0.273 \\
\hline & $(0.186)$ & $(0.151)$ & $(0.105)$ & $(0.070)$ & $(0.069)$ & $(0.078)$ & $(0.086)$ & $(0.092)$ & $(0.119)$ & $(0.258)$ \\
\hline \multirow[t]{2}{*}{ FDI } & 0.008 & 0.002 & 0.004 & 0.002 & 0.001 & -0.001 & -0.002 & -0.004 & -0.007 & 0.006 \\
\hline & $(0.009)$ & $(0.007)$ & $(0.005)$ & $(0.003)$ & $(0.003)$ & $(0.004)$ & $(0.004)$ & $(0.004)$ & $(0.006)$ & $(0.012)$ \\
\hline \multirow[t]{2}{*}{ EU } & $3.374 * * *$ & $3.622 * * *$ & $3.764 * * *$ & $3.846 * * *$ & $3.961 * * *$ & $4.008 * * *$ & $4.113 * * *$ & $4.166 * * *$ & $4.091 * * *$ & $4.305 * * *$ \\
\hline & $(0.201)$ & $(0.163)$ & $(0.114)$ & $(0.076)$ & $(0.074)$ & $(0.084)$ & $(0.093)$ & $(0.099)$ & $(0.129)$ & $(0.278)$ \\
\hline \multirow[t]{2}{*}{ RTEC } & $-0.104 * * *$ & $-0.113 * * *$ & $-0.113 * * *$ & $-0.111 * * *$ & $-0.108 * * *$ & $-0.106 * * *$ & $-0.103 * * *$ & $-0.102 * * *$ & $-0.099 * * *$ & $-0.096 * * *$ \\
\hline & $(0.006)$ & $(0.005)$ & $(0.003)$ & $(0.002)$ & $(0.002)$ & $(0.002)$ & $(0.003)$ & $(0.003)$ & $(0.004)$ & $(0.008)$ \\
\hline \multirow[t]{2}{*}{$\alpha_{0}$} & $-43.42 * *$ & -15.11 & -7.486 & -8.880 & $-14.00^{* *}$ & $-14.56^{*}$ & $-17.49 * *$ & -14.81 & -8.869 & 10.91 \\
\hline & $(18.63)$ & $(15.10)$ & $(10.53)$ & $(7.05)$ & $(6.868)$ & $(7.823)$ & $(8.579)$ & $(9.178)$ & $(11.92)$ & $(25.81)$ \\
\hline
\end{tabular}

